\title{
Study on the Different Effects of Power and Trailer Wheelsets on Wheel Polygonal Wear
}

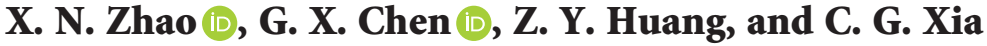 \\ The State Key Laboratory of Traction Power, Southwest Jiaotong University, Chengdu, Sichuan, China \\ Correspondence should be addressed to G. X. Chen; chen_guangx@163.com
}

Received 8 October 2019; Revised 12 September 2020; Accepted 5 October 2020; Published 19 October 2020

Academic Editor: Matteo Filippi

Copyright (c) 2020 X. N. Zhao et al. This is an open access article distributed under the Creative Commons Attribution License, which permits unrestricted use, distribution, and reproduction in any medium, provided the original work is properly cited.

\begin{abstract}
The wheels of power and trailer wheelset show different polygonal characteristics since their structures are obviously different. Therefore, the frictional self-excited vibration models of wheelset-track systems are established based on the viewpoint of the frictional self-excited vibration in reducing the wheel polygonal wear. Then, the motion stability of wheelset-track systems is studied by using the complex eigenvalue method. The results show that when the creep force between the wheel and rail is saturated, the unstable vibration frequency of the power wheelset is prone to induce 19-20th-order polygonal wear of the wheel, and the trailer wheelset is prone to induce 20-21th-order polygonal wear of the wheel. Meanwhile, the wheel polygonal wear can be effectively alleviated through changing the gearbox position of the power wheelset. And avoiding disc braking at high speeds can suppress the occurrence of wheel polygonal wear. In addition, the development tendency of wheel polygonal wear can be reduced by increasing the Young's modulus of the brake pad, but Poisson's ratio has little effect on the development tendency.
\end{abstract}

\section{Introduction}

With the rapid development of high-speed lines, high-speed train technology has also acquired great progress, which can ensure safe operation and good riding comfort. However, with the running distance increase of the vehicle, the wheels are constantly worn, and various defects are also present. The wheel wears in the circumferential direction, which will form the wheel polygonal wear. When a train with polygonal wheels runs at a high speed, the interaction between the wheel and rail is intensified, which directly affects the running performance of the high-speed vehicle. Meanwhile, the vehicle and track system components such as wheelsets, rails, and bearings will be seriously damaged, and their service lives will be severely shortened. Meanwhile, the high frequency vibration will be transmitted to the bogie through the wheelset and then transmitted to the vehicle body, affecting the passenger's comfort. In severe cases, the resonate oscillation probably takes place, which severely threatens the operation of the high-speed train. Foreign scholars in Germany and Sweden have studied the problem of wheel polygonal wear earlier. They have conducted systematic research on the formation, development, and dynamics of wheel polygonal wear through a large number of field tests and numerical simulation analysis. Kalousek and Johnson [1] confirmed the wheel polygon wear and proposed related mitigation measures to suppress the wheel polygonal wear by correcting the transverse profile of the rail and the wheel. Nielsen and Johansson [2-4] summarized the research progress and direction of wheel polygons and proposed corresponding prevention schemes for low-order polygons of wheels. Soua and Pascal [5] established the models and studied the wheel polygon problem through numerical simulation. His research shows that the wheel axle torsion has a great impact on the wheel polygonal wear. Meywerk [6] proved that the phase angle difference of polygons would affect the development speed of the wheel polygons by combining wheel-rail vibration and wheel tread wear. And he also verified the bending vibration frequency of wheelset, which will greatly affect the wheel polygonal wear. Meinke and Meinke [7] and his colleagues established a singledegree-of-freedom wheelset dynamics model and analyzed the formation and development of wheel polygonal wear by using unbalanced calculation and wear simulation. In China, 
some experts and scholars have also carried out a series of research works. Luo et al. [8] established the model of the wheel-rail system and carried out numerical analysis. Then, they found that the polygonal wear of the wheel was caused by the original irregularity of the wheel tread. They insisted that the polygonal wear of the wheel with initial irregularity would increase with the increase of running distance. Li et al. [9] analyzed the causes of the wheel polygons of subway vehicles and proposed improvement measures through field experimental data and numerical simulation. Ma et al. [10] established a linear motor metro vehicle model and analyzed it with the dynamic software to prove that the main excitation frequency and running speed of wheel-rail contact force have an important influence on the development of the wheel polygonal wear. Wu et al. [11] believed that there is a modal coupling resonance problem between the bogie wheelset and the frame around $580 \mathrm{~Hz}$, which is closely related to the formation of wheel polygonal wear. Chen $[12,13]$ put forward the viewpoint that wheel polygonal wear is caused by the frictional self-excited vibration of wheel-rail system in 2011. Then, this viewpoint was taken to study the polygonal wear of the wheels of high-speed trains. The predicted results and the measurement data on-site can be well unified.

It is well known that, during the running of high-speed trains, the problem of wheels in the polygonal wear becomes more and more obvious with continuous increase of operating mileage. It is urgent to study the formation, development, and dynamics of this phenomenon. A train with obvious polygonal wear characteristics in a highspeed railway operation section is selected for testing. The vibration acceleration of each part of the vehicle body is tested at a certain speed to determine the polygonal wear characteristics of the wheel. The results show that $[14,15]$ the performance characteristics of the power wheels are dominated by 19 th-order polygons, and the trailer wheels are dominated by 20 th-order polygons. The power bogie and the trailer bogie of the high-speed train are different, as shown in Figure 1. Vehicle bogie refers to an independent running structure composed of two or more wheelsets on the vehicle, which is equipped with springs and other components and can rotate relative to the vehicle body. The structures of the power wheelset and the trailer wheelset are significantly different. The power wheelset adopts the integral wheel and wheel-mounted brake disc with straight-spoke plates, and gearbox is mounted on the bearing seat. The trailer wheelset adopts s-shaped spoke plate integral wheel and axle-mounted brake disc, and three brake discs are mounted on the bearing seats. The wheel-rail saturated creep force causes the frictional self-excited vibration of the wheelset-track system, which leads to the wear of the wheel polygon. This study paper is based on this viewpoint. The frictional selfexcited vibration models of the wheelset-track system of power and trailer wheelsets are established. The effects of two different wheelsets on the wheel polygonal wear are calculated and analyzed, respectively. And finally, corresponding measures to suppress the wheel polygonal wear are proposed.

\section{Frictional Self-Excited Vibration Models of the Wheelset-Track System}

2.1. Wheelset Size. The basic composition of the wheelset is an axle and two identical wheels. Interference fit is adopted in the joint parts of axle and wheel. The power wheelset consists of two straight-spoke integral wheels, a hollow axle, a gearbox, and four wheel-mounted brake discs. And the trailer wheelset consists of two integral wheels of s-shaped curved spoke plate, a hollow axle, and three axle-mounted brake discs. Among them, the rolling circle diameter and spacing of the wheels are $920 \mathrm{~mm}$ and $1500 \mathrm{~mm}$, respectively. The inner pitch is $1353 \mathrm{~mm}$, the axle diameter center pitch is $2000 \mathrm{~mm}$, and the axle neck diameter is $130 \mathrm{~mm}$. Figure 2 is the wheelset size diagrams of high-speed trains.

\subsection{Contact Geometry Models of the Wheelset-Track System.} Figure 3 shows the wheelset-track contact geometric models of the power wheelset and the trailer wheelset. The power wheelset is mainly composed of two straight plate integral wheels, a hollow axle, a gearbox, and four wheel-mounted brake discs. The basic brake is in the form of a wheel disc brake. The trailer wheelset is mainly composed of two S-shaped curved plate integral wheels, a hollow axle, and three shaft-mounted brake discs. The basic brake is a unittype axle disc brake. In high-speed lines, the tracks are basically large radius curved tracks $(R \geq 6000 \mathrm{~m})$ or linear tracks. Therefore, the contact states of the wheels and rails on both sides are nearly identical. In Figure $3, \delta_{\mathrm{L}}$ and $\delta_{\mathrm{R}}$ are the contact angles between the left and right wheels and the rails. $N_{\mathrm{L}}$ and $N_{\mathrm{R}}$ are the normal forces generated by the left and right wheel-rail contacts, respectively. $F_{\text {SVL }}$ and $F_{\text {SVR }}$ are the vertical suspension forces acting on the left and right axle boxes, respectively. $F_{\mathrm{L}}$ and $F_{\mathrm{R}}$ are lateral creep forces generated by the left and right wheel-rail contacts, respectively. $K_{\mathrm{RV}}$ and $C_{\mathrm{RV}}$ are the vertical stiffness and damping of fasteners, respectively. $K_{\mathrm{RL}}$ and $C_{\mathrm{RL}}$ are the lateral stiffness and damping of fasteners, respectively. $K_{\mathrm{SV}}$ and $C_{\mathrm{SV}}$ are the vertical support stiffness and damping from the ballastless bed, respectively. $K_{\mathrm{SL}}$ and $C_{\mathrm{SL}}$ are the lateral support stiffness and damping from the ballastless bed, respectively.

\subsection{Finite Element Models of the Wheelset-Track System.} In this paper, the solid models of wheelset and track are established firstly, and then their finite element models are established through ABAQUS. The element type is incompatible element, C3D8I. The finite element models are shown in Figure 4 . The division of the mesh uses structure and sweeping techniques. The total numbers of nodes and elements of the power wheelset-track system are 1425463 and 450983, respectively. The total numbers of nodes and elements of the trailer wheelset-track system are 1452261 and 470059, respectively. The axle is a hollow axle made of EA4T steel, and the wheel is a rolling steel integral wheel made of ER8 steel. The grinding diameter of the power and trailer wheel is $90 \mathrm{~mm}$ and $60 \mathrm{~mm}$, respectively. The tread is in the form of $\mathrm{S} 1002 \mathrm{CN}$. The interference between the axle and the wheel is $0.2 \mathrm{~mm}$, and the interference between the 


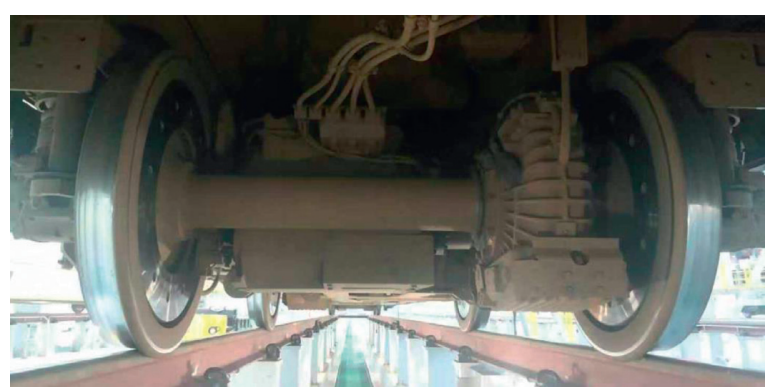

(a)

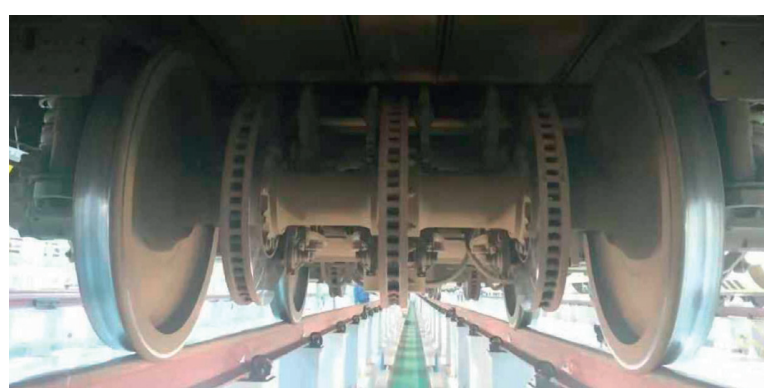

(b)

FIGURE 1: Two wheelset forms: (a) the power wheelset, (b) the trailer wheelset.

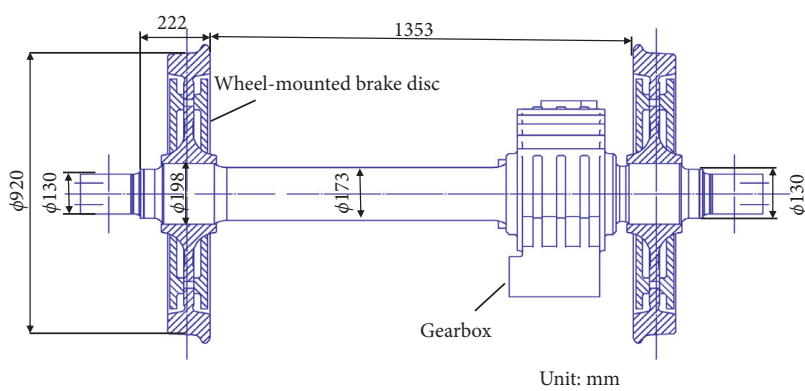

(a)

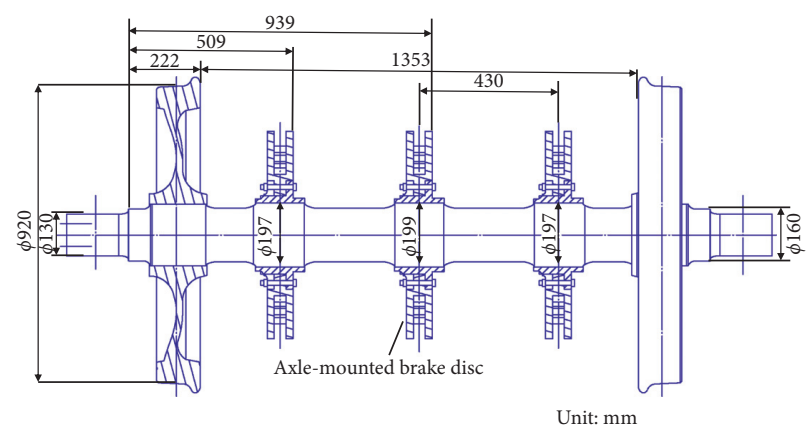

(b)

Figure 2: The wheelset size diagrams of high-speed trains: (a) the power wheelset, (b) the trailer wheelset.

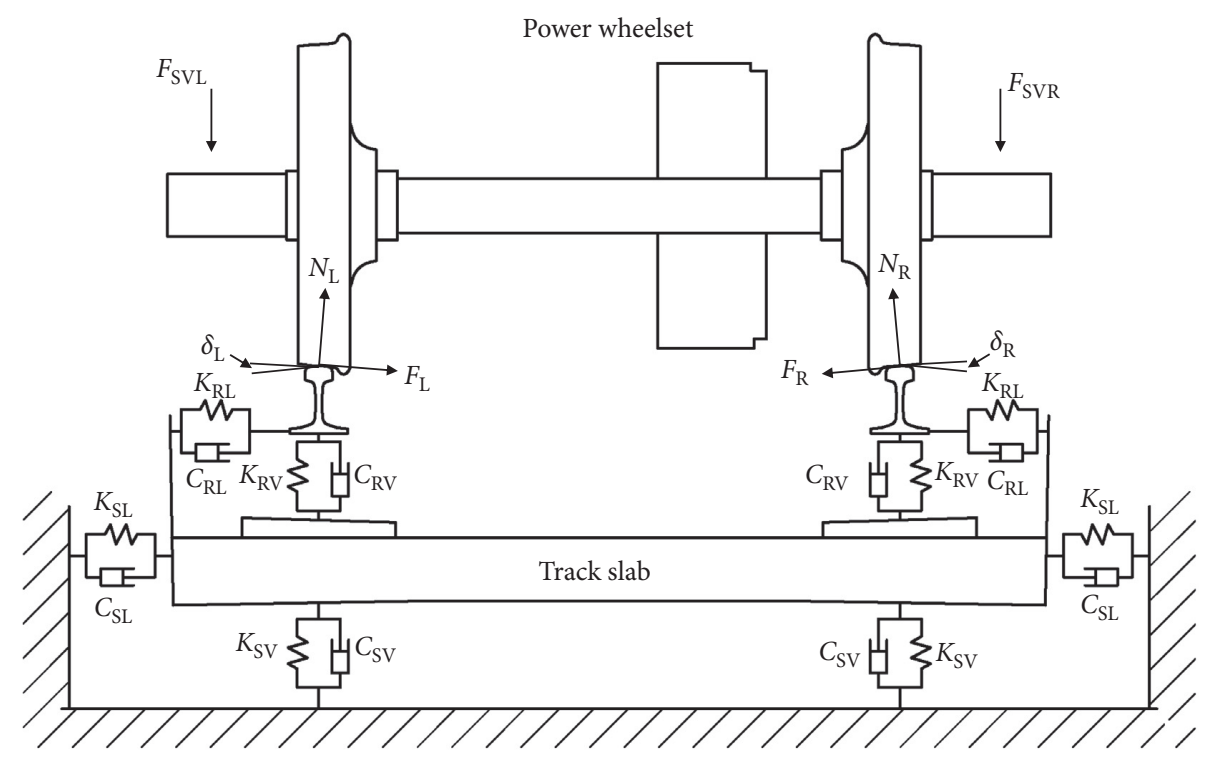

(a)

FIGURE 3: Continued. 


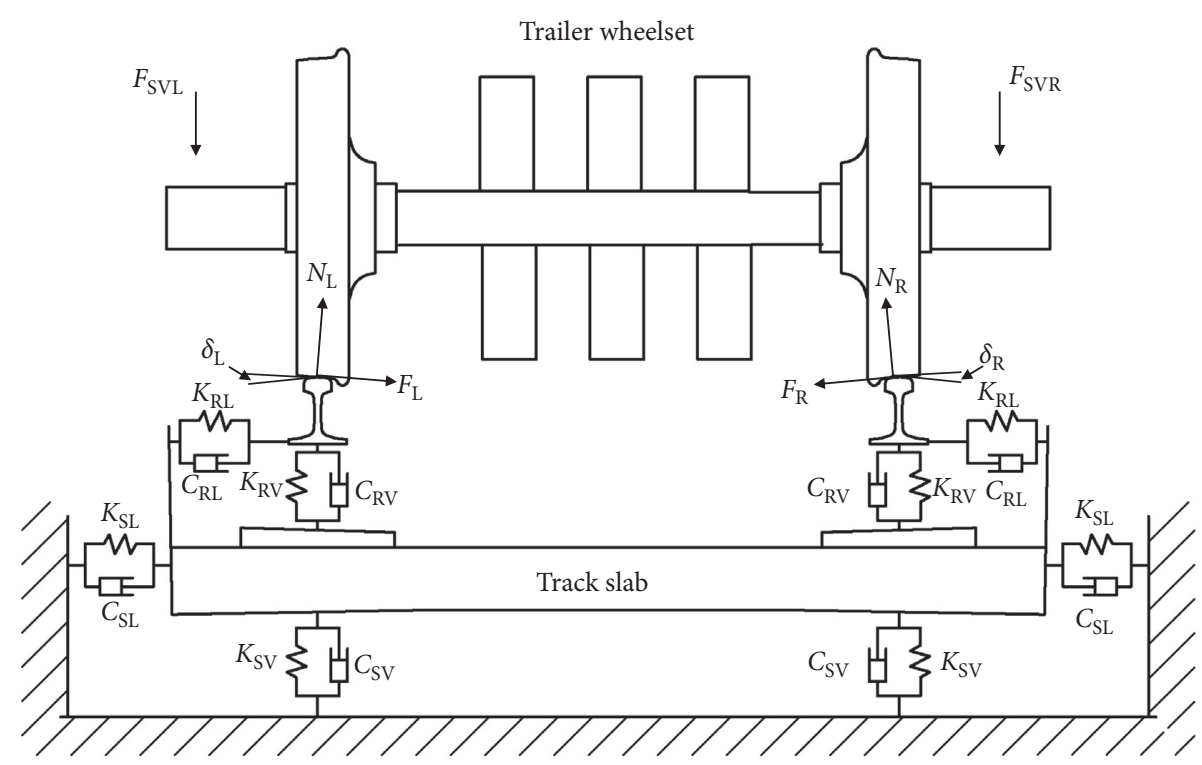

(b)

FIGURE 3: Contact geometry models of wheelset-track system: (a) the power wheelset, (b) the trailer wheelset.

axle and the axle-mounted disc is $0.15 \mathrm{~mm}$. The length of the rail is $l=36 \mathrm{~m}$, and the specification of $60 \mathrm{~kg} / \mathrm{m}$ is selected. The adhesion coefficient between the wheel and rail is $\mu=0.45$, and the rail bottom slope is $1 / 40$. The ballastless track of CRTS III type slab is used. The fasteners are WJ-7 fasteners, and the fastener node spacing is $l_{\mathrm{s}}=650 \mathrm{~mm}$. Table 1 shows the material properties of the parts in the models. The rail is connected with the sleeper by the spring and damping elements. The sleeper is connected with the track slab by the method of tie connection, and the bottom support of track slab is realized by the spring and damping elements.

In the study of this paper, the suspension force of the wheelset is chosen to be $120 \mathrm{kN}$. The suspension force is achieved by applying a load to the reference point by means of the reference point coupling the end face of the axle. Then, the kinematic coupling method is used to constrain the longitudinal direction of the track. The interference between the wheel and the axle is restrained by press-fitting. Interference value is 0.1 . The stiffness and damping values in the models are given below: the lateral stiffness and damping of the fasteners are $K_{\mathrm{RL}}=20 \mathrm{MN} / \mathrm{m}$ and $C_{\mathrm{RL}}=10 \mathrm{kN} \mathrm{s} / \mathrm{m}$, and the vertical stiffness and damping are $K_{\mathrm{RV}}=50.0 \mathrm{MN} / \mathrm{m}$ and $C_{\mathrm{RV}}=20 \mathrm{kN} \mathrm{s} / \mathrm{m}$, respectively. Supporting vertical stiffness and damping values of the track bed are $K_{\mathrm{SV}}=9.375 \times 10^{3} \mathrm{MN} / \mathrm{m}$ and $C_{\mathrm{SV}}=276 \mathrm{kN} \mathrm{s} / \mathrm{m}$, and the lateral stiffness and damping values are $K_{\mathrm{SL}}=90 \mathrm{MN} / \mathrm{m}$ and $C_{\mathrm{SL}}=55 \mathrm{kN} \mathrm{s} / \mathrm{m}$, respectively.

2.4. Frictional Self-Excited Vibration Analysis Method. For China's high-speed trains, the polygonal wear of similar order will occur at the same time both on the power and trailer wheels. We think that the similar wear characteristics of the power and trailer wheels may be caused by an operation factor of the train and at the same time causing abnormal wheel-rail interaction. Each axle of a high-speed train is equipped with an antilock device, but not for the lowspeed train. This shows that there is a high probability that the high-speed train will slide between the wheels and rails during traction and braking. Previous studies have shown that the adhesion coefficient between the wheel and rail decreases greatly in rainy and snowy weather, which is easy to cause sliding in traction and braking conditions [16]. Most of the rail corrugation of high-speed railways occurs in the train braking section [17], and the grinding rails are rail corrugation, and the grinding wheels produce polygonal wear. Therefore, we can reasonably assume that brake slip occurs between the wheel and rail under extreme conditions, and this study is conducted under this assumption.

At present, the analysis of frictional self-excited vibration mainly includes two kinds of finite element analysis methods: complex eigenvalue analysis and transient dynamic analysis [18]. In this paper, the unstable vibration of the system is analyzed by the complex eigenvalue method built in the software ABAQUS. The frictional self-excited vibration equation of the system can be written as

$$
\mathbf{M} \ddot{\mathbf{x}}+\mathbf{C} \dot{\mathbf{x}}+\mathbf{K x}=0
$$

where $\mathbf{M}$ is the mass matrix of the system, $\mathbf{C}$ is the damping matrix of the system, and $\mathbf{K}$ is the stiffness matrix of the system. The three matrices are symmetric, and $x$ represents the node displacement vector. When $\mathbf{M}, \mathbf{C}$ and $\mathbf{K}$ are symmetric matrices, the real part of the eigenvalue corresponding to equation (1) should be negative. In this case, the performance of the system is stable. When the friction force is taken into account, rewrite equation (1) as follows:

$$
\mathbf{M}_{\mathbf{r}} \ddot{\mathbf{x}}+\mathbf{C}_{\mathbf{r}} \dot{\mathbf{x}}+\mathbf{K}_{\mathbf{r}} \mathbf{x}=0 .
$$

In the equation, $\mathbf{M}_{\mathbf{r}}, \mathbf{C}_{\mathbf{r}}$ and $\mathbf{K}_{\mathbf{r}}$ are asymmetric matrices due to frictional coupling. Next, the characteristic equation of equation (2) is given as follows: 

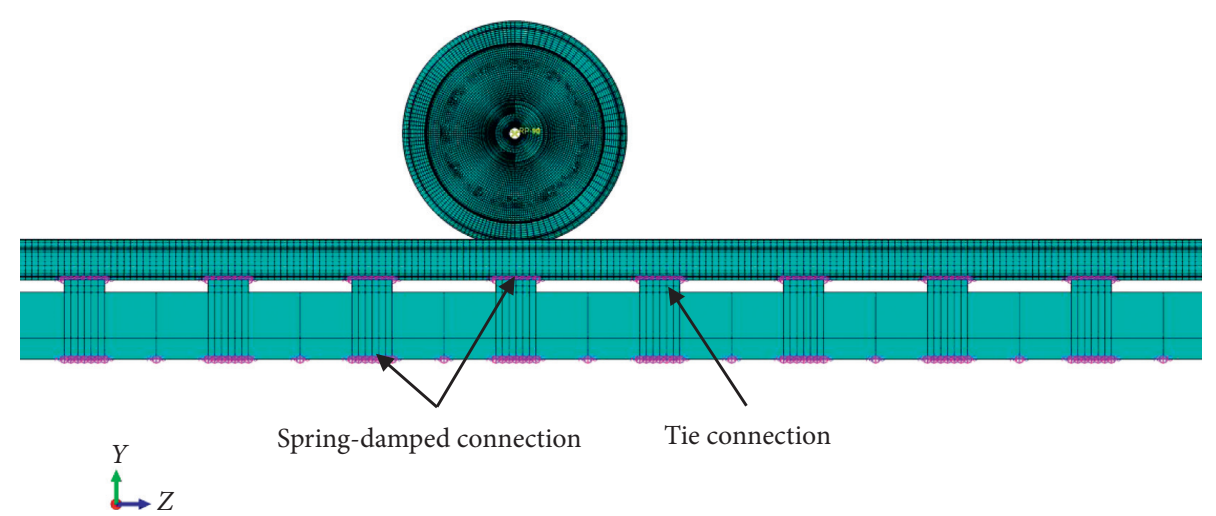

(a)

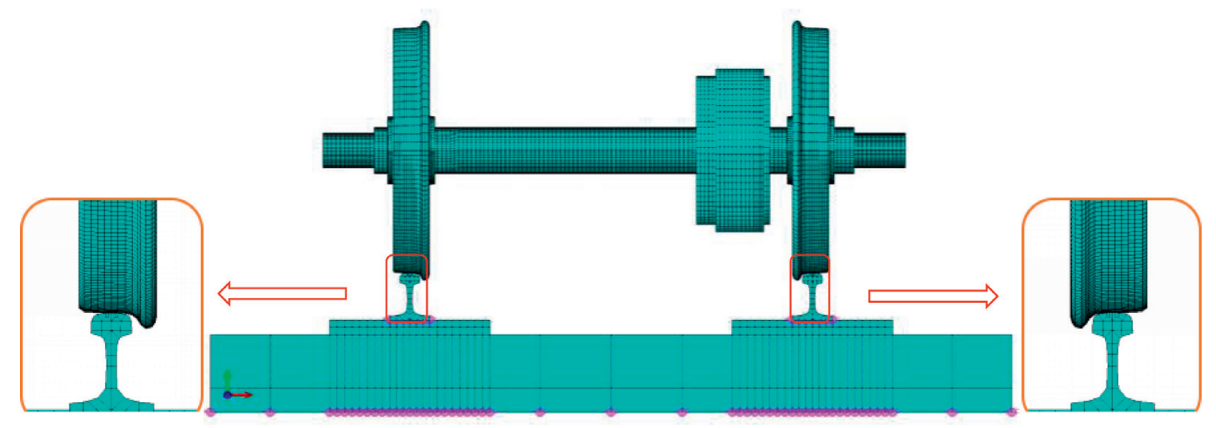

(b)

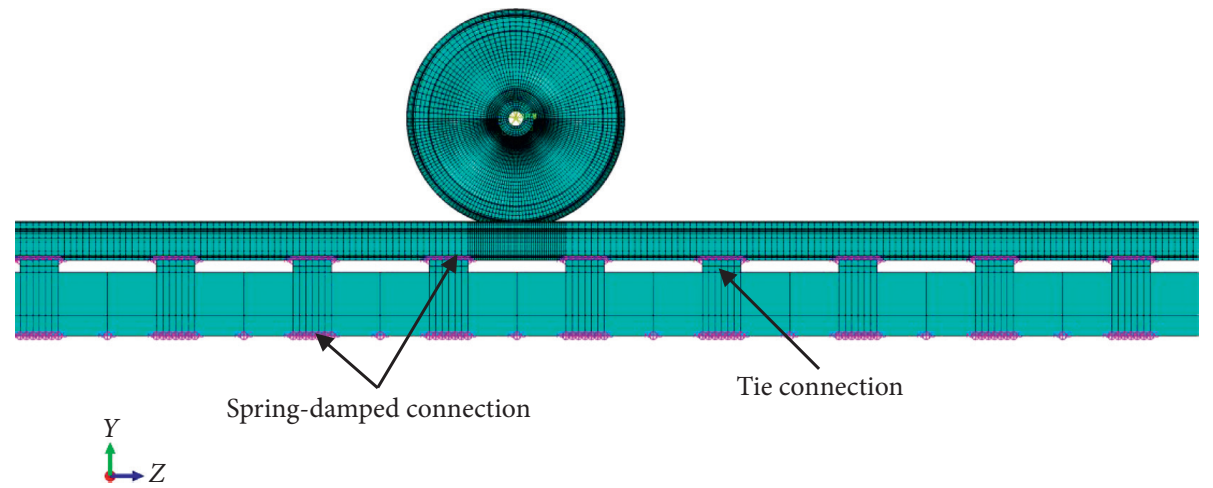

(c)

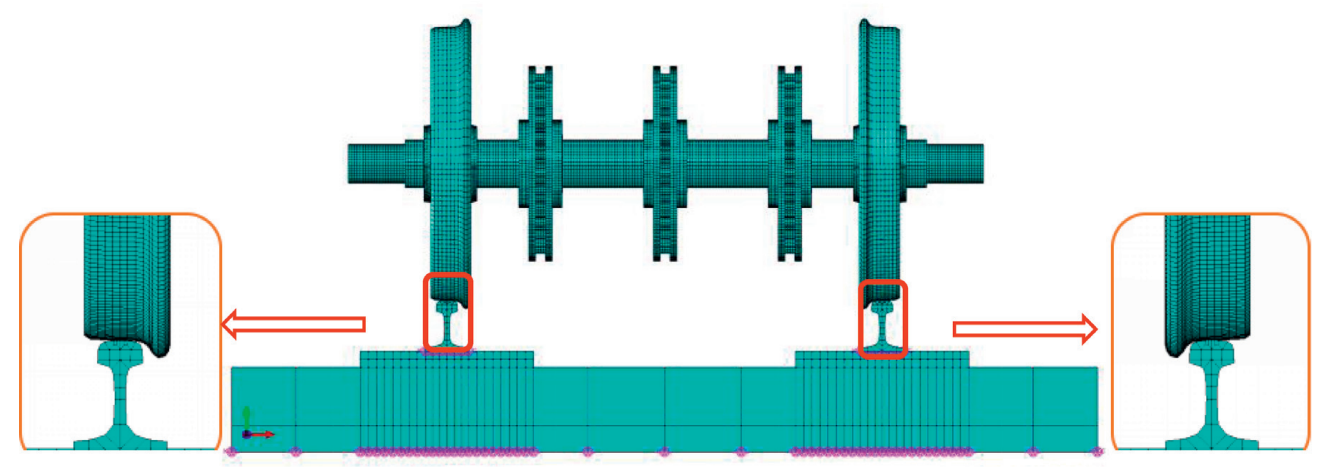

(d)

Figure 4: Finite element models of the power and trailer wheelset-track system: (a) left view of the power wheelset-track system, (b) front view of the power wheelset-track system and contact details between wheel and rail, (c) left view of the trailer wheelset-track system, (d) front view of the trailer wheelset-track system and contact details between wheel and rail. 
TABLE 1: Material properties.

\begin{tabular}{lccc}
\hline Part & $E(\mathrm{GPa})$ & Poisson's ratio & $\rho\left(\mathrm{kg} / \mathrm{m}^{3}\right)$ \\
\hline Wheel & 210 & 0.3 & $7.8 \times 10^{3}$ \\
Axle & 206 & 0.29 & $7.8 \times 10^{3}$ \\
Disc & 190 & 0.27 & $7.3 \times 10^{3}$ \\
Rail & 205.9 & 0.3 & $7.79 \times 10^{3}$ \\
Sleeper & 35 & 0.3 & $2.5 \times 10^{3}$ \\
Slab & 36 & 0.167 & $2.5 \times 10^{3}$ \\
\hline
\end{tabular}

$$
\left(\mathbf{M}_{\mathbf{r}} \lambda^{2}+\mathbf{C}_{\mathbf{r}} \lambda+\mathbf{K}_{\mathbf{r}}\right) \varnothing=0
$$

where $\lambda$ and $\varnothing$ are the eigenvalues and eigenvectors corresponding to the system, respectively. Regardless of the asymmetrical part of the matrix $\mathbf{K}_{\mathbf{r}}$ and $\mathbf{C}_{\mathbf{r}}$, the eigenvalues of the symmetrical part of the corresponding matrix can be obtained, and the eigenvalues obtained under this condition are pure imaginary numbers. The complex eigenvalue $\lambda$ at this time is a pure imaginary number, and the eigenvalue problem can be simplified as

$$
\left(\omega\left[\mathbf{M}_{\mathbf{r}}\right]+\left[\mathbf{K}_{\mathbf{s}}\right]\right) z=0,
$$

where $\mathbf{K}_{\mathbf{s}}$ is a symmetric stiffness matrix. The subspace method is used to solve the symmetric eigenvalue problem. At this time, the original matrix can be projected by the subspace of the real feature vector $z$ :

$$
\begin{aligned}
{\left[\mathbf{M}_{r}^{*}\right] } & =\left[z_{1}, z_{2}, \ldots, z_{n}\right]^{T}\left[\mathbf{M}_{r}\right]\left[z_{1}, z_{2}, \ldots, z_{n}\right], \\
{\left[\mathbf{C}_{r}^{*}\right] } & =\left[z_{1}, z_{2}, \ldots, z_{n}\right]^{T}\left[\mathbf{C}_{r}\right]\left[z_{1}, z_{2}, \ldots, z_{n}\right], \\
{\left[\mathbf{K}_{r}^{*}\right] } & =\left[z_{1}, z_{2}, \ldots, z_{n}\right]^{T}\left[\mathbf{K}_{r}\right]\left[z_{1}, z_{2}, \ldots, z_{n}\right] .
\end{aligned}
$$

The simplified eigenvalue problem is described as follows:

$$
\left(\left[\mathbf{M}_{r}^{*}\right] \lambda^{2}+\left[\mathbf{C}_{r}^{*}\right] \lambda+\left[\mathbf{K}_{r}^{*}\right]\right) \mathbf{y}^{*}=0 .
$$

Then, the QZ method is used to solve the generalized asymmetric eigenvalue problem. The eigenvalues of the original system can be restored as follows:

$$
\mathbf{y}^{k}=\left[z_{1}, z_{2}, \ldots, z_{n}\right] \mathbf{y}^{* k} \text {. }
$$

where $\mathbf{y}^{k}$ is the estimated value of the $k$ th order eigenvector of the original system. According to the eigenvalue equation, the general solution can be found as

$$
x(t)=\sum \varnothing_{i} \exp \left(\lambda_{i} t\right)=\sum \varnothing_{i} \exp \left(\left(\beta_{i}+j \omega_{i}\right) t\right),
$$

where $\lambda_{i}=\beta_{i}+j \omega_{i}$ is the $i$ th complex eigenvalue. $\beta_{i}$ represents the real part of the eigenvalue, $j$ represents the imaginary unit, and $\omega_{i}$ represents the imaginary part of the eigenvalue. It is well known that the complex eigenvalue method can be used to analyze the unstable vibration of the system. The method is to judge the possibility of unstable vibration of the system according to whether the real part of the complex eigenvalue is positive. The eigenvalue with positive real part can be obtained if equation (3) has an asymmetric coefficient matrix. When the real part $\beta_{i}$ is a positive number, the system may generate frictional self-excited vibration. This means that you give the system a small excitation, and the system oscillates more and more violently with time. At the same time, the tendency of frictional self-excited vibration will increase with the increase of the real part of the eigenvalue. The effective damping ratio of the system can also be used to evaluate the tendency of frictional self-excited vibration. The definition is given below:

$$
\xi_{i}=\frac{-\beta_{i}}{\left(\pi\left|\omega_{i}\right|\right)}
$$

When the effective damping ratio $\xi_{i}$ is negative, the system tends to be unstable, and frictional self-excited vibration is likely to occur. It needs to be mentioned that it is generally accepted in the brake squeal research community that the smaller the effective damping ratio is, the more likely the corresponding unstable vibration occurs. However, some researches also showed that not only the squeal corresponding to the smallest absolute value of the effective damping ratio can occur, but sometimes the squeal corresponding to a larger negative effective damping ratio can also occur $[19,20]$. The steps of the complex eigenvalue analysis method in finite element software ABAQUS are given below:

(1) Apply a suspension force on the wheelset to perform a nonlinear static analysis on the wheelset-track system. (In Sections 2.2 and 2.3, the driving force must be applied simultaneously by the brake caliper.).

(2) Apply the sliding speed on the wheelset to achieve saturated creep force between the wheel and rail for nonlinear static analysis.

(3) Extract the natural frequency without friction coupling for normal mode analysis.

(4) Perform complex eigenvalue analysis in combination with the influence of friction coupling.

\section{Results and Analysis}

3.1. Analysis of Saturated Creep Force between Wheel and Rail. When traction and braking are carried out during operation of the high-speed trains, the longitudinal creep force between the wheel and rail is easily saturated. In the paper, we assume that wheel slips on the rail when traction or braking is performed at a speed of $v=250 \mathrm{~km} / \mathrm{h}$. In this case, the longitudinal creep force between the wheel and rail is saturated. The unstable vibration distributions of the wheelsettrack system are shown in Figure 5. For the power wheelset, it can be seen from Figure 5(a) that the wheelset-track system has three frequencies with an effective damping ratio $\xi$ less than zero, namely, $f_{1}=228.68 \mathrm{~Hz}, f_{2}=363.82 \mathrm{~Hz}$ and $f_{3}=470.57 \mathrm{~Hz}$. According to the above complex eigenvalue analysis method, it is known that the wheelset-track system is likely to have unstable vibration at these frequencies. Among them, the absolute value of the effective damping ratio $\xi$ corresponding to $f_{3}=470.57 \mathrm{~Hz}$ is the largest, and the wheelset-track system is more easily to have unstable vibration at this frequency. For the trailer wheelset, it can be 


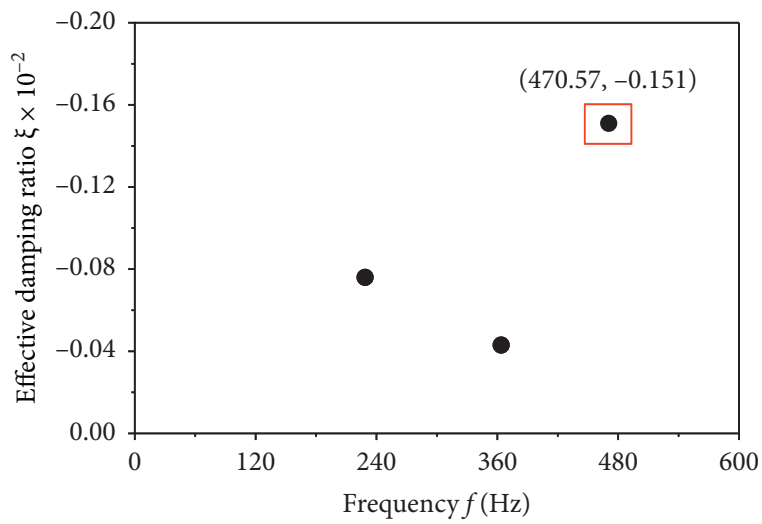

(a)

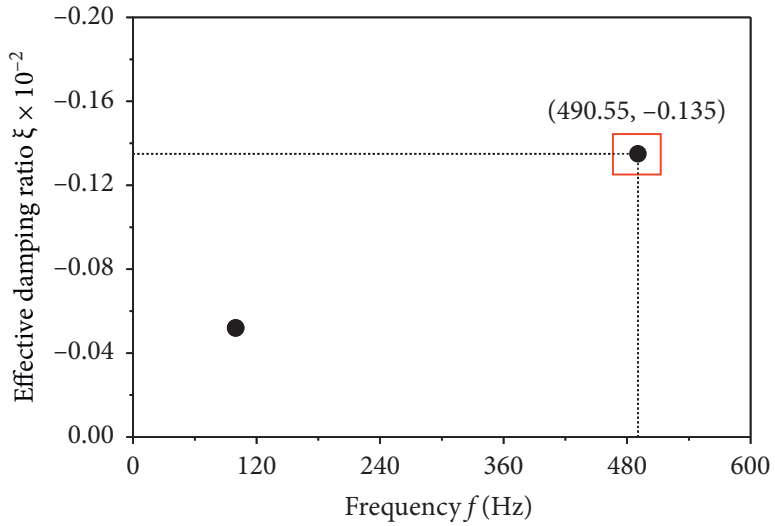

(b)

FIGURE 5: Frequency distributions of frictional self-excited vibration of the wheelset-track system: (a) the power wheelset, (b) the trailer wheelset.

seen from Figure 5(b) that there are two unstable vibration frequencies in the wheelset-track system, namely, $f_{1}=99.705 \mathrm{~Hz}$ and $f_{2}=490.55 \mathrm{~Hz}$. The absolute value of the effective damping ratio $\xi$ corresponding to $f_{2}=490.55 \mathrm{~Hz}$ is the larger than $f_{1}=99.705 \mathrm{~Hz}$. Figure 6 shows the unstable vibration modes of the power wheelset at $f_{3}=470.57 \mathrm{~Hz}$ and the trailer wheelset at $f_{2}=490.55 \mathrm{~Hz}$, respectively. It can be clearly seen that the deformation of the wheel tread is obvious, and the wheel polygonal wear is likely to occur. According to the formula,

$$
f=n \frac{v}{\pi D}
$$

where $n$ is the order of the wheel polygon. When the highspeed train is running at a speed of $v=250 \mathrm{~km} / \mathrm{h}$, the result shows that the unstable vibration frequency of the power wheelset is easy to induce the 19-20th-order wheel polygonal wear, and the unstable vibration frequency of the trailer wheelset is easy to induce the 20-21th-order wheel polygonal wear. In this case, when the train passes at a speed of $v=300 \mathrm{~km} / \mathrm{h}$, the excited vibration frequency is about 564 $588 \mathrm{~Hz}$. This is very consistent with the field measurements $[14,15]$.

In the existing studies [21], the mounting position of gearbox on the power wheelset of the subway has less influence on rail corrugation. For the high-speed trains, the following is an analysis of the effect of the gearbox mounting position of the power wheelset on the polygonal wear. Figure 7 shows the unstable vibration distribution of the power wheelset when the gearbox mounting position gradually approaches the middle. Figure 7 (a) shows the unstable vibration of the original mounting position of the gearbox. At this time, we assume that the distance of the gearbox from the centerline of the axle is $L$. From Figure $7(b)$ we can see that the unstable vibration trend is decreasing. In Figure $7(\mathrm{c})$, the wheelset-track system does not show an effective damping ratio $\xi<0$. It can be seen that when the gearbox is mounting at the center of the axle, the unstable vibration tendency of the wheelset-track system is least. This means that when the gearbox is mounted in the middle symmetrical position, the generation of the polygonal wear of the power wheel can effectively suppress. It is worth noting that, comparing the results of existing research [20], we get different results. Due to the differences in the materials and structure of the wheelsets between high-speed train and metro train, there are also great differences in their unstable vibration performance.

Sufficient theoretical accumulation is the foundation of engineering progress. The research in this manuscript is reflected in theoretical research. The manuscript mainly considers the influence of the saturation of creep force between wheel and rail on the unstable vibration of the wheelset-track system. In the sense of engineering guidance, it also needs to consider its feasibility from other aspects in the future, such as fatigue strength, the equilibrium of weight, and the space interference of bogie components.

\subsection{Analysis of Saturated Creep Force between Wheel and Rail} Caused by Disc Brake. Friction braking is one of the most common braking methods used in high-speed trains in various countries. The friction braking of the high-speed trains is mainly manifested in the form of the disc brake. The brake caliper generates a driving force through the brake cylinder such that the brake pad contacts the friction surface of the brake disc. Friction is generated by mutual contact, and the frictional force is converted into a braking force to decelerate and stop the train. When the relative sliding between the brake pad and the brake disc occurs, the brake system will generate intense vibration [22-24]. At the same time, this frictional force will eventually be transformed into the braking force between the wheel and rail through the wheel-rail relationship. When the braking force is too large, the creep force is likely to reach saturation. Therefore, when two friction systems are coupled, the unstable vibration of the wheelset-track system will change. In this paper, finite element models of the coupled frictional self-excited vibration of the disc brake system and the wheelset-track system are established, which is shown in Figure 8. The brake pad is a copper-based powder metallurgy material with an outer diameter of $d=725 \mathrm{~mm}$, and then it is attached to the brake disc in a face-to-face manner. The density of the 

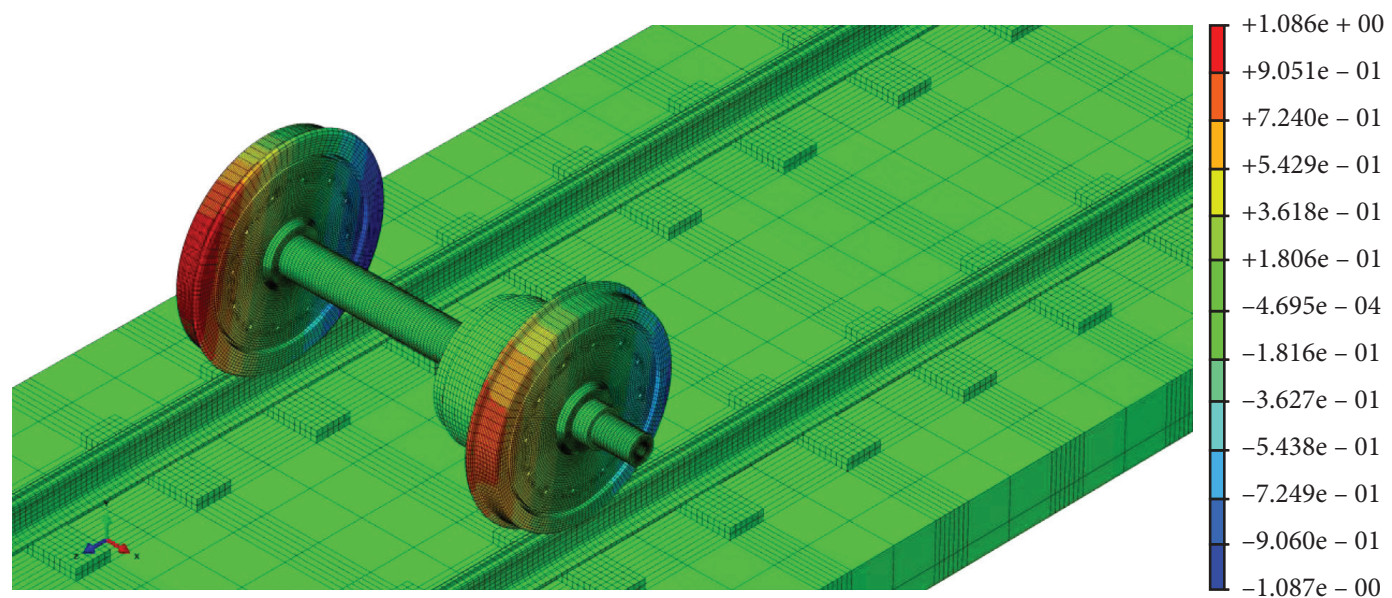

Max: $+1.086 \mathrm{e}+00$

Node: PART-10-1.40

Min: $-1.087 \mathrm{e}+00$

Node: PART-10-1.7

(a)
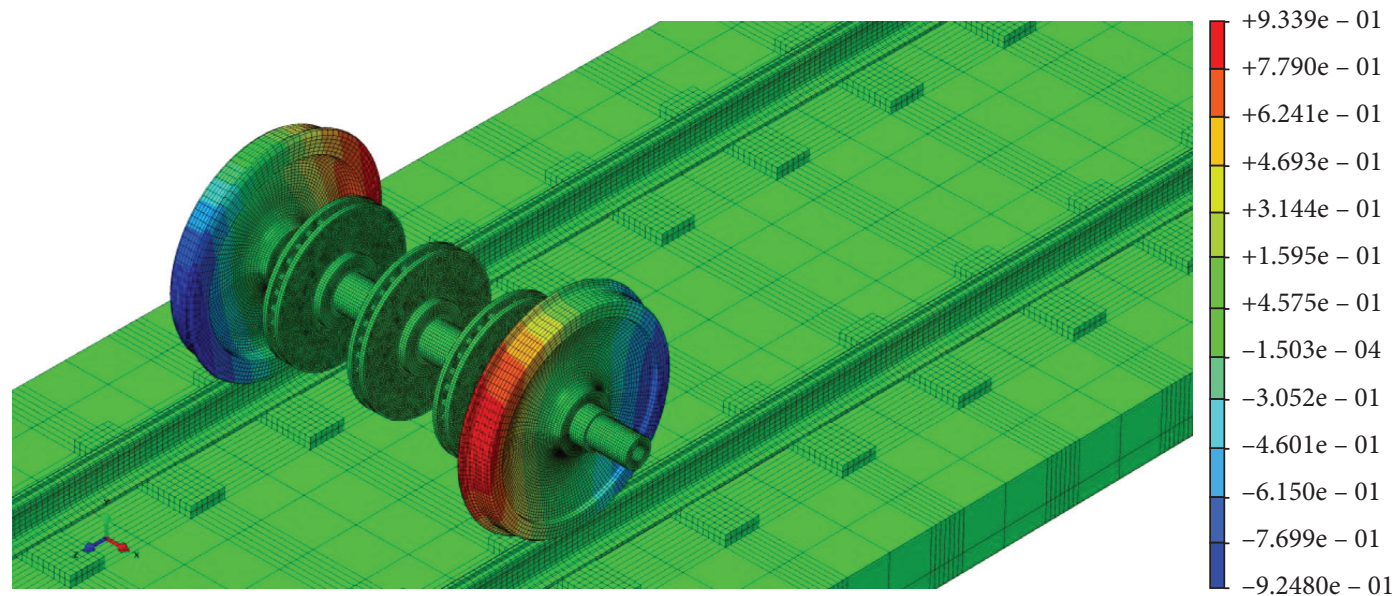

Max: $+9.339 \mathrm{e}+01$

Node: LUNDUI-1.1160

Min: $-9.248 \mathrm{e}+01$

Node: LUNDUI-1.669

(b)

FIgURE 6: Unstable vibration modes of the wheelset-track system: (a) the power wheelset, $f=470.57 \mathrm{~Hz}, \xi=-0.00151$, (b) the trailer wheelset, $f=490.55 \mathrm{~Hz}, \xi=-0.00135$.

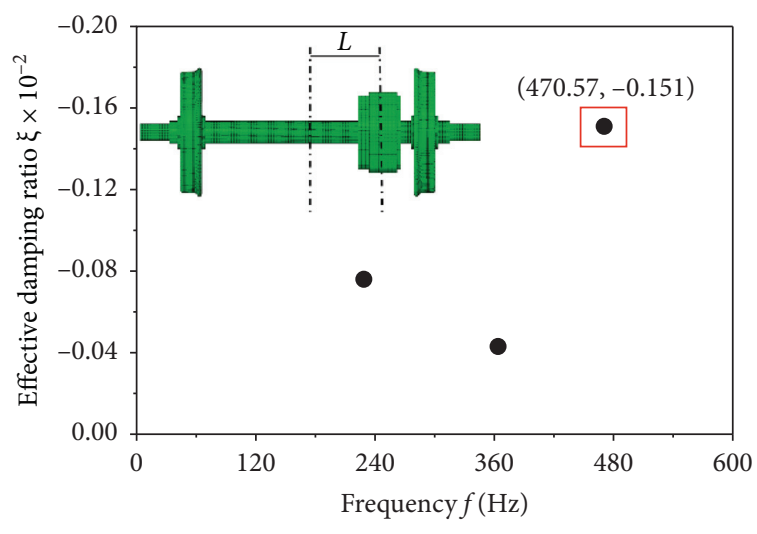

(a)

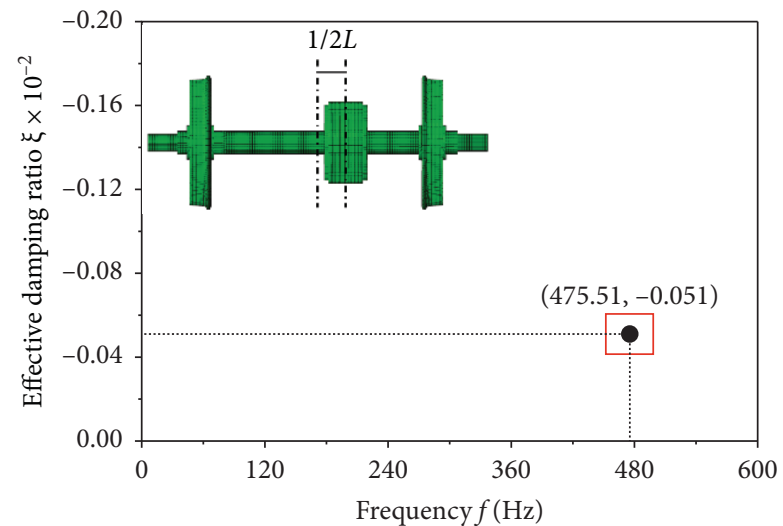

(b)

Figure 7: Continued. 


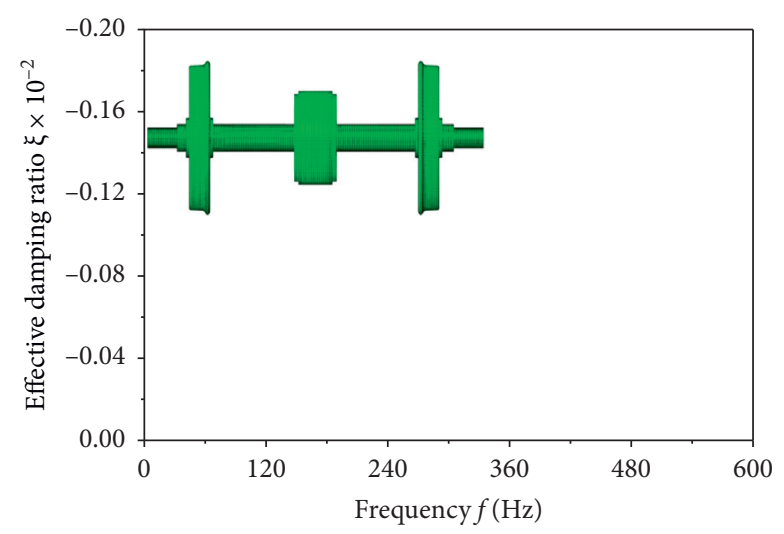

(c)

FIGURE 7: Frequency distributions of frictional self-excited vibration of the power wheelset-track system in different gearbox mounting positions: (a) original mounting position, (b) $1 / 2 L$ mounting position, (c) symmetrical mounting position.
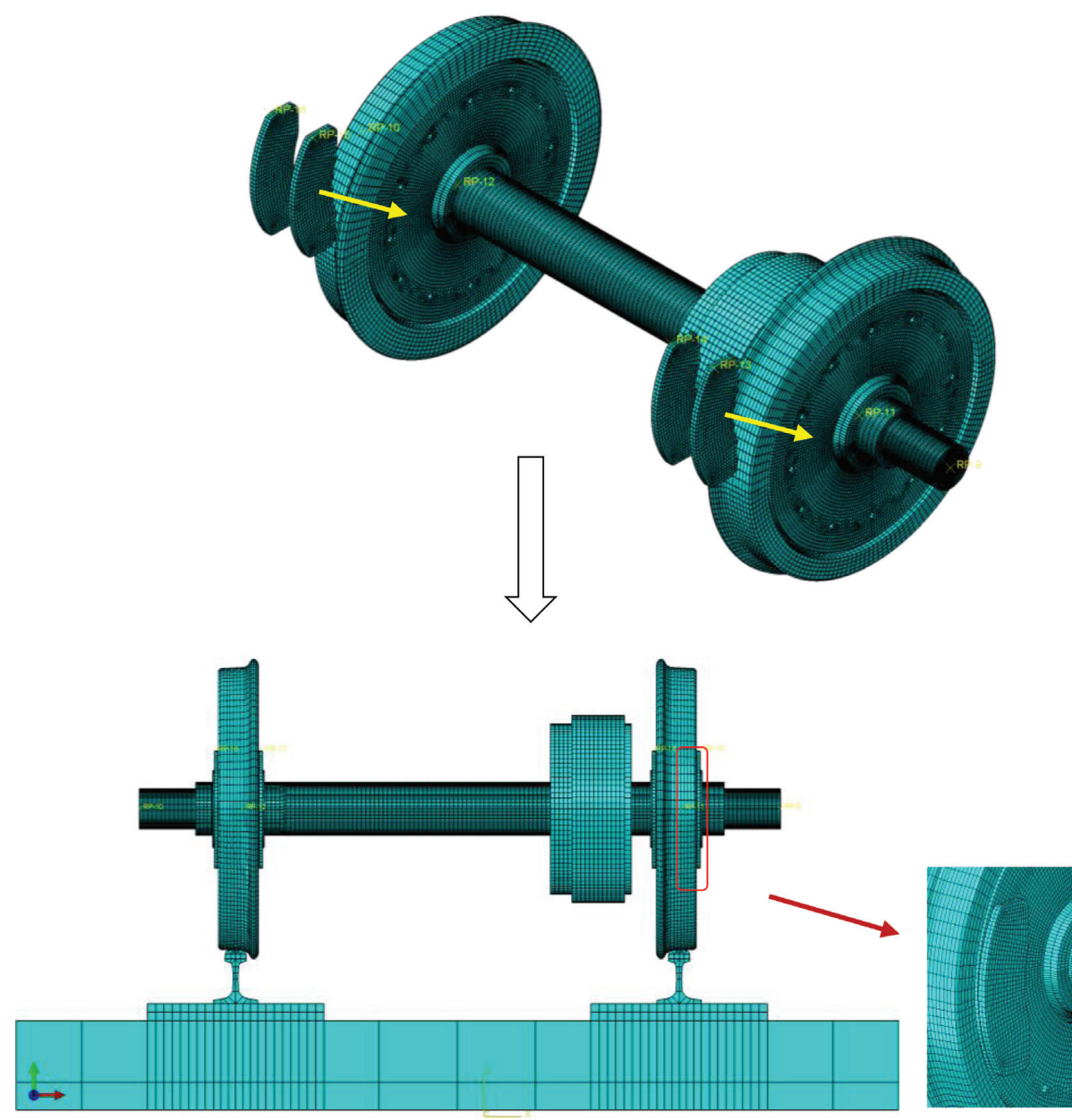

(a)

FIGURE 8: Continued. 


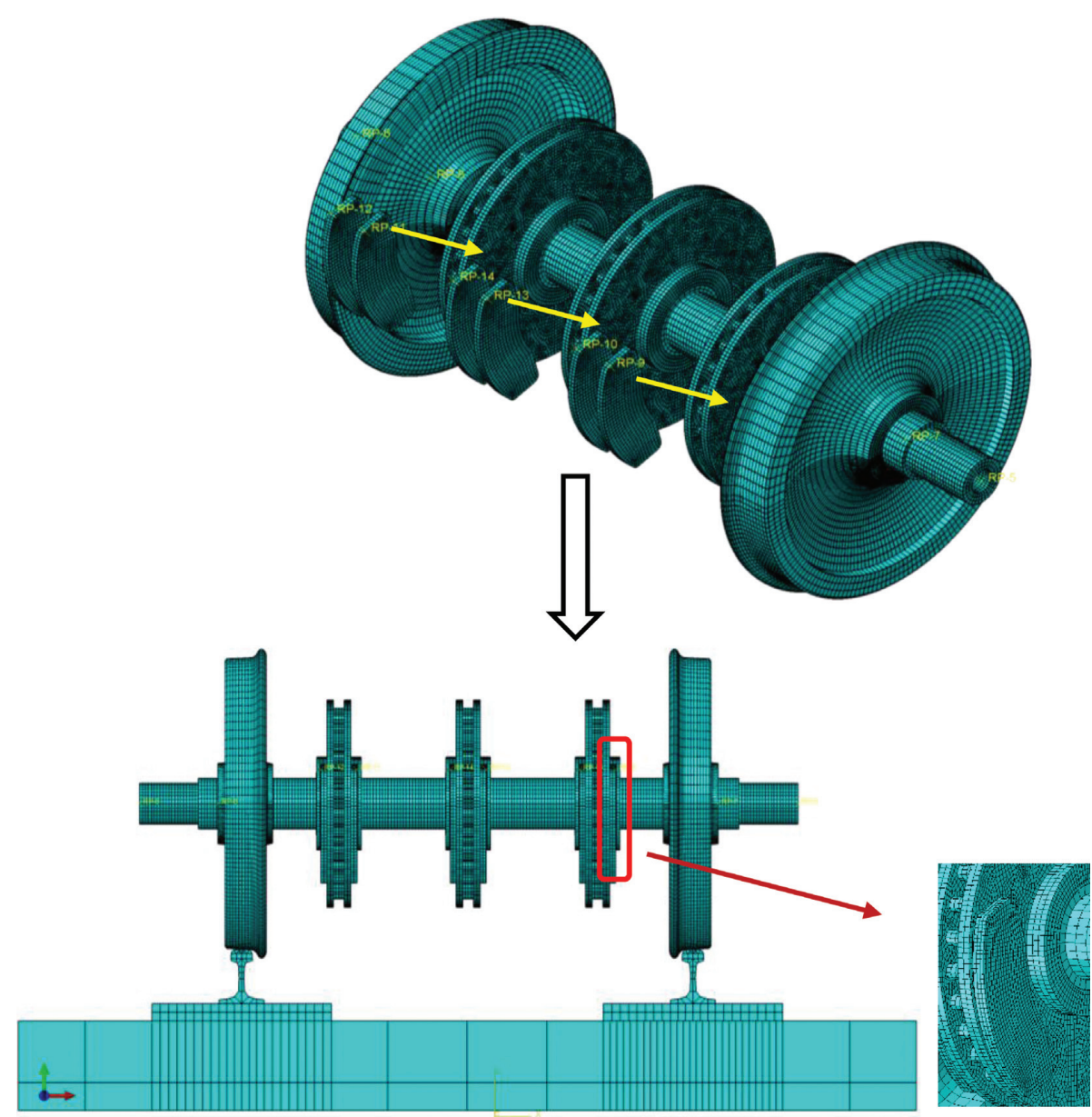

(b)

Figure 8: The finite element models of the frictional self-excited vibration of wheelset-track system with the brake coupling: (a) the power wheelset, (b) the trailer wheelset.

selected material is $\rho=5250 \mathrm{~kg} / \mathrm{m}^{3}$, Young's modulus is $E=1.8 \times 10^{11} \mathrm{~Pa}$, and Poisson's ratio is $\gamma=0.3$.Then, we study the unstable vibration of the wheelset-track system in this case.

Figure 9 shows the distribution of the effective damping ratio of the wheelset-track system when the above two sets of friction systems are taken into consideration. For the power wheelset, it can be seen in Figure 9(a) that the unstable vibration frequency $f=490.71 \mathrm{~Hz}$ appears in the wheelsettrack system, and its vibration mode shows a severe deformation of the wheel tread. It can be seen in Figure 9(b) that the wheelset-track system of the trailer wheelset has 6 unstable vibration frequencies, and the effective damping ratio $\xi$ corresponding to $f=561.38 \mathrm{~Hz}$ is the largest. It indicates that the unstable vibration of the wheelset-track system is most likely to occur at this frequency. From its unstable vibration mode, it can be seen that the wheel tread is seriously deformed. According to equation (6), when the train is running at $v=250-300 \mathrm{~km} / \mathrm{h}$, the unstable vibration frequency of the moving wheel pair is easy to produce the 17-20th-order wheel polygonal wear, and the unstable vibration frequency of the trailer wheel pair is easy to produce 19-23th-order wheel polygonal wear. Therefore, avoiding the use of disc brakes in the high-speed zone can not only avoid the increase of braking power due to heat dissipation limitation, but also reduce the tendency of the wheel polygonal wear.

\subsection{Influence of the Material Parameters of the Brake Pad on} Unstable Vibration. Previous studies have shown that $[25,26]$ the material of the friction pair has a significant effect on the unstable vibration of braking squeal noise. In this section, the power wheelset is taken as the research object. The influence of Young's modulus and Poisson's ratio of the brake material on the trend of the wheel polygonal wear is studied, as shown in Figure 10. It can be seen in Figure 10(a) that as Young's modulus of the brake pad increases, the unstable vibration frequency of the wheelsettrack system does not change obviously. However, the corresponding effective damping ratio $\xi$ decreases. That is to say, the tendency of the unstable vibration of the wheelsettrack system is weakening. Therefore, the trend of wheel polygonal wear is decreasing. Figure 10(b) shows the effect of Poisson's ratio on the unstable vibration trend of the wheelset-track system. It can be seen in the figure that, with 


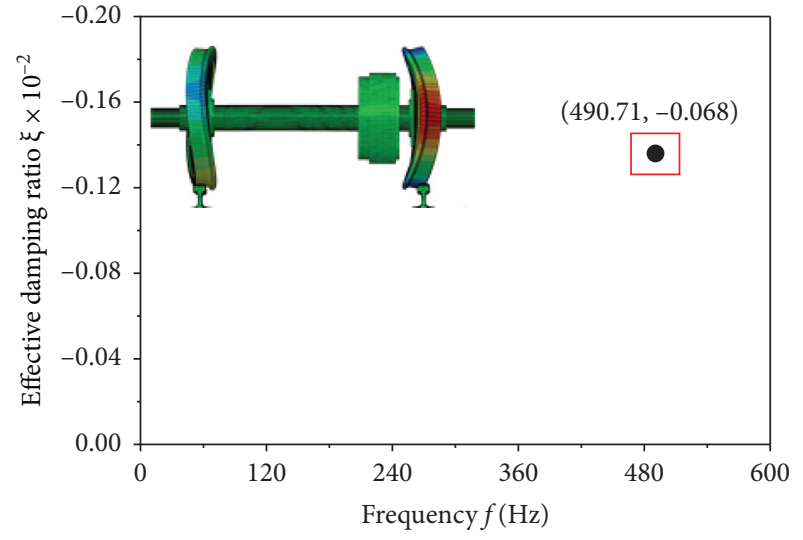

(a)

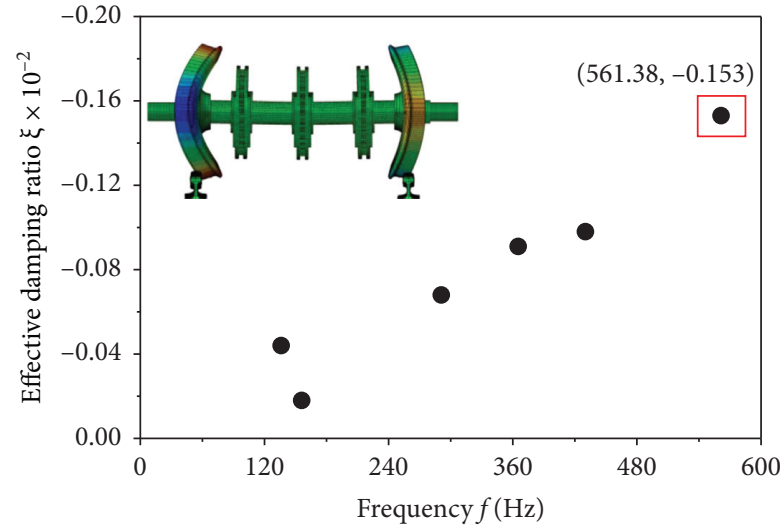

(b)

FIGURE 9: Frequency distributions of frictional self-excited vibration of wheelset-track system with the brake coupling: (a) the power wheelset and (b) the trailer wheelset.

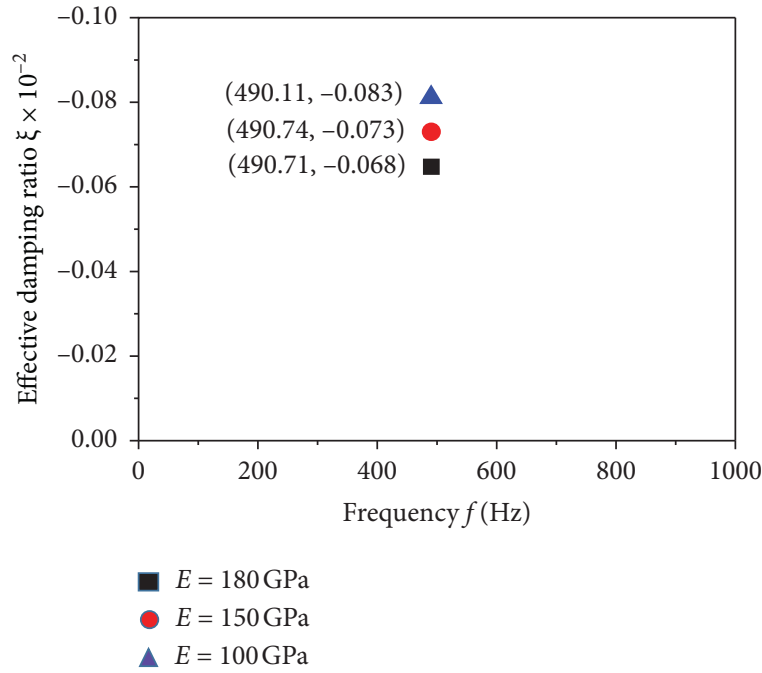

(a)

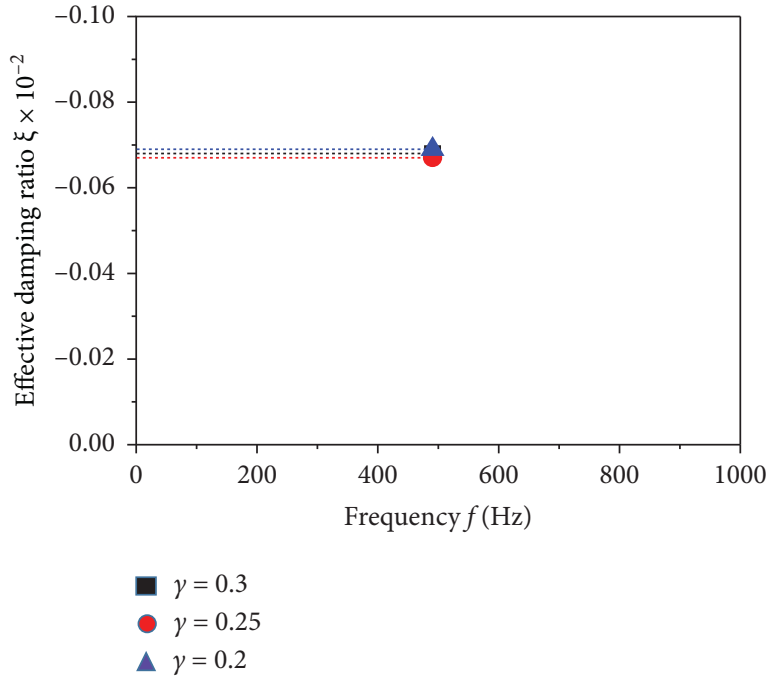

(b)

FIGURE 10: Effect of different material parameters of the brake pad on the frictional self-excited vibration of the wheelset-track system: (a) effect of different Young's modulus and (b) effect of different Poisson's ratio.

the change of the Poisson's ratio, the unstable vibration trend of the wheelset-track system is basically unchanged. Therefore, appropriately increasing Young's modulus $E$ of the brake pad material can reduce the development trend of the wheel polygonal wear, and changing Poisson's ratio $\gamma$ of the brake pad material has little effect on the development trend of the wheel polygonal wear.

\section{Conclusion}

In this paper, the wheelset-track system models of the power wheelset and the trailer wheelset are established. By using complex eigenvalue method, the influence of different wheelset structure on wheel polygonal wear was analyzed. The conclusions obtained are as follows:
(1) When traction or braking is performed at a speed of $v=250 \mathrm{~km} / \mathrm{h}$, the unstable vibration of the power wheelset is probably to induce the wheel 19-20thorder polygonal wear, and the unstable vibration of the trailer wheelset is probably to induce the wheel 20-21th-order polygonal wear. The mounting position of the gearbox has a significant influence on the unstable vibration of the power wheelset. When the gearbox is close to the center of the axle, the polygonal wear trend of the power wheels can be effectively suppressed.

(2) The unstable vibration of the wheel changes greatly when the disc brake system is coupled with the wheelset-track system. Avoiding the use of disc brakes in the high-speed zone can not only avoid the 
increase of braking power due to heat dissipation limitation, but also reduce the tendency of the wheel polygonal wear.

(3) Appropriately increasing Young's modulus E of the brake pad material can reduce the development trend of the wheel polygonal wear. But Poisson's ratio $\gamma$ of the brake pad material has little influence on the development trend of the wheel polygonal wear.

\section{Data Availability}

The data used to support the findings of this study are included within the article.

\section{Conflicts of Interest}

The authors declare that there are no conflicts of interest regarding the publication of this paper.

\section{Acknowledgments}

The authors thank the financial support from National Natural Science Foundation of China (No. 51775461).

\section{References}

[1] J. Kalousek and K. L. Johnson, "An investigation of short pitch wheel and rail corrugations on the Vancouver mass transit system," Proceedings of the Institution of Mechanical Engineers, Part F: Journal of Rail and Rapid Transit, vol. 206, no. 2, pp. 127-135, 1992.

[2] J. C. O. Nielsen, Out-of-round Railway Wheels, pp. 245-279, Wheel/rail Interface Handbook Woodhead Publishing Cambridge, Cambridge, UK, 2009.

[3] A. Johansson, "Out-of-round railway wheels-literature survey, field tests and numerical simulations," 2003.

[4] J. C. O. Nielsen and A. Johansson, "Out-of-round railway wheels-a literature survey," Proceedings of the Institution of Mechanical Engineers, Part F: Journal of Rail and Rapid Transit, vol. 214, no. 2, pp. 79-91, 2000.

[5] B. Soua and J. P. Pascal, "Computation of the 3D wear of the wheels in a high speed bogie," pp. 21-40, INRETS-LTN, Arcueil, France, 1995.

[6] M. Meywerk, "Polygonalization of railway wheels," Archive of Applied Mechanics (Ingenieur Archiv), vol. 69, no. 2, pp. 105-120, 1999.

[7] P. Meinke and S. Meinke, "Polygonalization of wheel treads caused by static and dynamic imbalances," Journal of Sound and Vibration, vol. 227, no. 5, pp. 979-986, 1999.

[8] R. Luo, J. Zeng, P. B. Wu et al., "Simulation and analysis of wheel out-of-roundness wear of high-speed train," Journal of the China Railway Society, vol. 32, no. 05, pp. 30-35, 2010.

[9] W. Li, Y. Y. Li, X. F. Zhang et al., "Mechanism of the polygonal wear of metro train wheels," Journal of Mechanical Engineering, vol. 49, no. 18, pp. 17-22, 2013.

[10] W. Ma, S. H. Luo, and R. R. Song, "Analyses of the form reason of wheel polygonization of subway vehicle," Journal of Mechanical Engineering, vol. 48, no. 24, pp. 106-111, 2012.

[11] Y. Wu, J. Han, J. Liu et al., "Effect of high-speed train polygonal wheels on wheel/rail contact force and bogie vibration," Journal of Mechanical Engineering, vol. 54, no. 4, pp. 37-46, 2018.

[12] G. X. Chen, X. S. Jin, P. B. Wu et al., "Finite element study on the generation mechanism of polygonal wear of railway wheels," Journal of the China Railway Society, vol. 33, no. 01, pp. 14-18, 2011.

[13] X. N. Zhao, G. X. Chen, J. Z. Lv, S. Zhang, B. W. Wu, and Q. Zhu, "Study on the mechanism for the wheel polygonal wear of high-speed trains in terms of the frictional self-excited vibration theory," Wear, vol. 426-427, pp. 1820-1827, 2019.

[14] C. Y. Song, W. L. Shen, X. F. Li et al., "On the influencing factors and inhibiting measures of wheel polygons of highspeed EMUs," China Railway, no. 11, pp. 33-40, 2017.

[15] D. D. Li and H. Y. Dai, "Research on wheel polygonization based on rail modal oscillation analysis," Electric Drive for Locomotives, no. 02, pp. 61-66, 2018.

[16] J. Wang, K. Y. Wang, and J. X. Liu, "Analysis of the influence of adhesion coefficient of rain and snow on locomotive safety performance," Journal of Chongqing University of Technology (Natural Science), vol. 27, no. 09, pp. 17-21, 2013.

[17] L. Q. Wang, "Research on high-speed railway rail corrugated wear and tear," Journal of Shijiazhuang Tiedao University (Natural Science), vol. 26, no. 4, pp. 83-86, 2013.

[18] Y. Yuan, "An eigenvalue analysis approach to brake squeal problem," 1996.

[19] S. W. Kung, G. Stelzer, V. Belsky et al., "Brake squeal analysis incorporating contact conditions and other nonlinear effects," SAE Technical Paper Series, 2003.

[20] Y. K. Wu, B. Tang, Z. Y. Xiang, H. H. Qian, J. L. Mo, and Z. R. Zhou, "Brake squeal of a high-speed train for different friction block configurations," Applied Acoustics, vol. 171, p. 107540, 2021.

[21] X. L. Cui, G. X. Chen, and H. G. Yang, "Influence of wheelset structure and fastener stiffness on rail corrugation," Journal of Southwest Jiaotong University, vol. 52, no. 01, pp. 112-117, 2017.

[22] M. Paliwal, A. Mahajan, J. Don, T. Chu, and P. Filip, "Noise and vibration analysis of a disc-brake system using a stick-slip friction model involving coupling stiffness," Journal of Sound and Vibration, vol. 282, no. 3-5, pp. 1273-1284, 2005.

[23] H. Y. Dai, "Analysis on chatter in brake system of railway vehicle," Journal of Engineering Design, vol. 13, no. 01, pp. 41-44, 2006.

[24] F. Dohnal and F. Verhulst, "Averaging in vibration suppression by parametric stiffness excitation," Nonlinear Dynamics, vol. 54, no. 3, pp. 231-248, 2008.

[25] Y. Hu, P. P. Huang, and G. X. Chen, "Study of brake shoes parameters on brake squeal propensity based on complex eigenvalue method," Electric Drive for Locomotives, no. 04, pp. 23-25, 2015.

[26] S. Oberst and J. C. S. Lai, "Statistical analysis of brake squeal noise," Journal of Sound and Vibration, vol. 330, no. 12, pp. 2978-2994, 2011. 